\title{
Analytic Hierarchy Process Case Study - Solution Source Selection
}

\author{
William Townsend, Jacksonville University ${ }^{1}$, USA
}

\begin{abstract}
The analytic hierarchy process has been used to evaluate and prioritize decision criteria for over 25 years. This case examines an application of the process to a source selection problem in an environment with several stakeholder organizations with disparate assessments of the relative weighting of various decision criteria. The process served as an effective way to establish consensus and produce a supportable decision model.
\end{abstract}

Keywords: Source selection, Analytic hierarchy process

\section{INTRODUCTION}

$\mathrm{n}$ the winter of 2007, Steve Masters ${ }^{2}$ knew a decision needed to be made. Steve was the Vice President of Marriott International Fulfillment Services (MIFS) and a Vice President of Ritz-Carlton. He was the organizational sponsor for implementing the new Ritz-Carlton gift card program. Gift cards had become a significant revenue stream for Marriott International. The hotel and resort chain had implemented an automated system allowing for credit card type gift cards to be sold and redeemed for most of its hotel brands. The cards were widely available for purchase at hotel properties, retail outlets and online, and redeemable for rooms and services at Marriott locations worldwide. The automated gift cards provided Masters daily sales, redemption and liability reporting for the product line by property. Detailed tracking of specific sales or redemptions could be provided for audit purposes. The Marriott gift cards could be redeemed for products and services at all of the 15 brands in the Marriott International group, except for the Ritz-Carlton hotel chain.

Marriott International is a worldwide organization composed of not only Marriott Hotels, but Fairfield, Inn, and 13 other hospitality industry brands (Marriott International, 2008). Marriott International is a diversified firm in the hotel, resort, restaurant and executive residence industries. Marriott's hotel ventures began in the Washington, DC area with the first motel near National Airport in 1957. It currently has about 3000 lodging properties located in the US and 67 foreign countries. It employs more than 151,000 people worldwide.

During the fall of 2006, MIFS had funded a project planning and requirements development effort to automate the Ritz-Carton gift card program. This effort was designed to more accurately issue, track and realize revenue from the Ritz-Carton gift card sales activity. Another MIFS objective of the Ritz-Carlton gift card project was to automate the existing paper gift card process and more closely integrate the effort into similar activities for the other Marriott brands.

While Ritz-Carlton hotels had been part of Marriott International since 1995, they considered themselves significantly different in image and clientele from Marriott and the other hotel brands. Since its inception in 1927 in Boston, Ritz-Carlton hotels had positioned itself as an upscale property focused on providing first class service to its guests (Ritz-Carlton, 2008). Up until the 1960s, the hotel was very formal. Strict dress codes were enforced for all guests and guests were regularly checked to see if they were in the Social Register or Who's Who. Their focus on personalized service to their guests extended to all aspects of the organization's culture and self-image. This corporate culture led them to defend their separate identity after they had become part of Marriott International. This discrete identity led them to believe that their gift card program required a separate identity and approach from that followed by the rest of the Marriott brands. As a result, they used a conventional paper gift certificate approach, issued and redeemed at specific properties rather than the Marriott gift card solution. 
The use of a paper gift card was somewhat inconsistent with Ritz-Carlton's image of high quality personalized service, and by 2007 it was increasingly apparent that it was a problem for the financial an management processes at Marriott. Paper certificates presented financial and operational problems around issues of security, issuance and redemption and liability accounting. These were all issues that could be remediated and melded into Marriott's overall financial reporting through the use of a stored value card.

Marriott International had used a stored value card solution provider for some time. They had experienced mixed results. The features and availability of the gift cards had changed rapidly in the past few years, with the marketing possibilities expanding even faster. Marriott's solution provider had experienced some difficulty in keeping up with modifications of availability, features and reporting occurring in the industry. As a result, Marriott's gift card features had limited the extent of their expansion at a time when they had great hopes for gift card product expansion. Marriott's gift card transactions were also cleared through a traditional credit card clearing system, rather than more current private networks offered by some stored value card solution providers. This increased Marriott's clearing cost for each transaction. For these reasons, there was a building desire at Marriott toward exploring the next generation solution in the coming months.

\section{REQUIREMENTS ANALYSIS RESULTS}

In the fall of 2006, Marriott International conducted a requirements analysis effort to quantify the specifics required of an automated gift card system for Ritz-Carlton.

This requirements analysis was conducted by a project team from across the Marriott International and Ritz-Carlton organizations. A project manager from Marriott's Information Resources (IR) organization headed this interdisciplinary team up. The primary objective would be to fully capture and prioritize the requirements from 11 stakeholder organizations and memorialize them in a way that potential solution vendors could respond to. These stakeholder organizations composed a Steering Committee to guide requirements development (Figure 1).

\section{Figure 1: Stakeholder Organizations for Ritz-Carlton Gift Card Requirements Project}

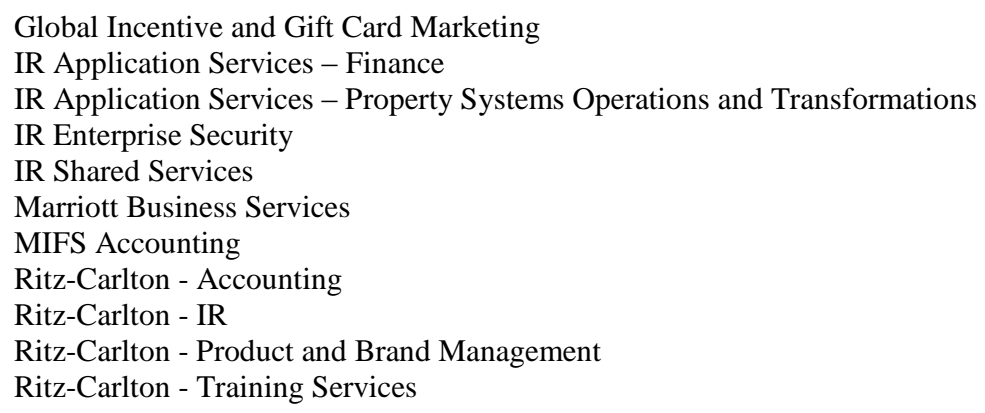

The requirements process followed a modified RUP process to distill and document the requirements and obtain agreement across stakeholder groups, as shown in Figure 2. An iterative approach was used to bring to light subtleties involved in each requirement and to obtain final consensus.

The final product of the requirements analysis contained a number of use cases, supplemental specification, system requirements and management plans and reports. It total 62 requirements were documented, with 39 must haves, 15 desired and 8 postponed. 
Figure 2: Requirements Analysis Process

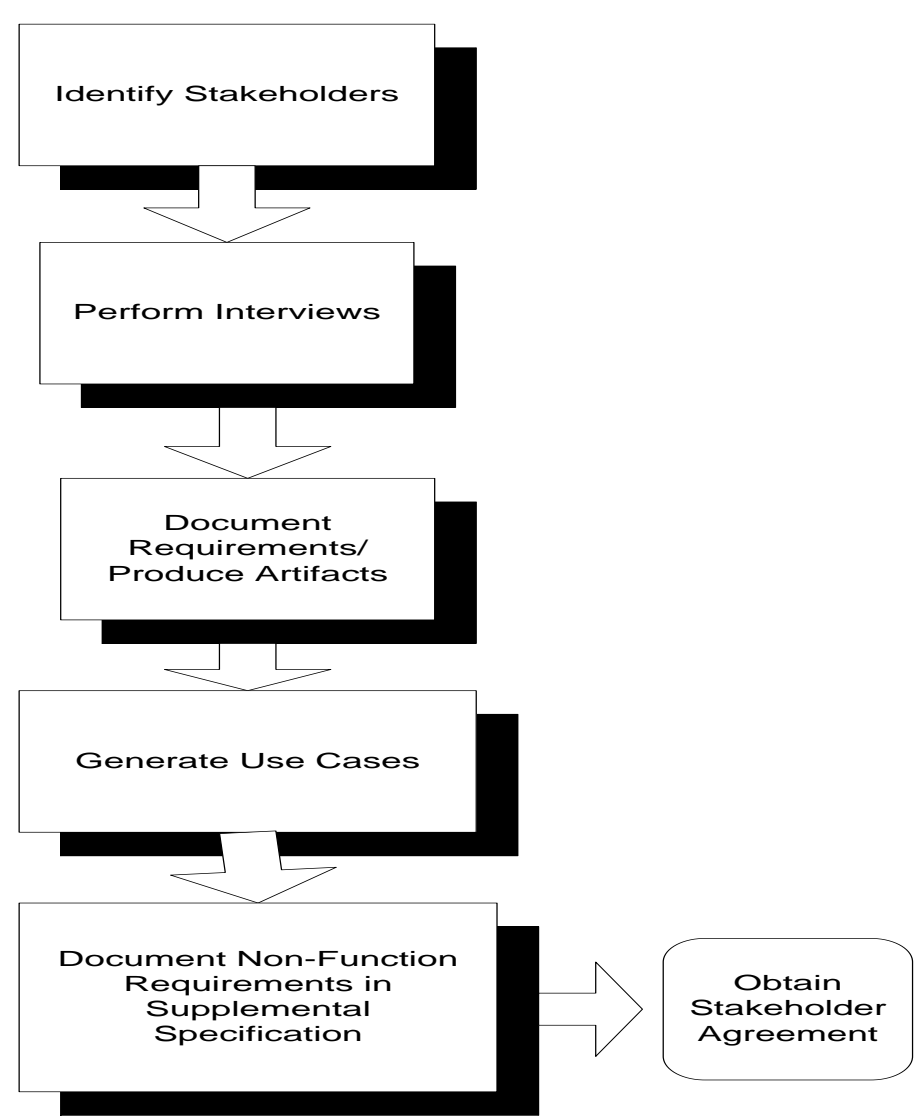

\section{MARKET SURVEY}

Stored value card solution providers were a relatively young industry with most vendor products dating from the 1990s. Marriott commissioned a national management consulting firm to perform an initial screen of the market offering for stored value card vendors. This market was a quickly evolving one with new vendors and new functionality available monthly. This meant that the survey conducted in 2006 had a finite shelf-life in that the products available and their comparative attributes were rapidly changing. In order to abbreviate the overall implementation length of the gift card program, this survey was conducted in parallel with the requirements analysis efforts.

Ten potential stored value card vendors were identified and interviewed at length by the consulting firm. Data was gathered on a variety of business, product, customer experience and technological topics.

Ten business and process criteria were examined as a first step toward source comparison. These criteria and their priorities are described in Figure 3. In addition, the sources were compared on a set of 19 technical criteria and 31 functional criteria. These later criteria were not identical to the final product of the requirements analysis nor had they been prioritized since the market survey and the formal requirements analysis were parallel processes. 
Figure 3: Initial Comparison Factors for Market Survey

\begin{tabular}{|l|c|}
\hline \multicolumn{1}{|c|}{ Criteria } & Priority \\
\hline Analysis Phase & High \\
\hline Business Process Development & High \\
\hline Conversion & High \\
\hline Performance and SLA & Critical \\
\hline Training & High \\
\hline Organization transition & High \\
\hline Reports & Medium \\
\hline Environment & High \\
\hline System Integrity & High \\
\hline Cost Comparison & High \\
\hline
\end{tabular}

Based upon the results of the market analysis and the requirements analysis phase, three vendors were selected to respond to a preliminary set of requirements documents. These responses would provide the basis of evaluation in the analytic hierarchy process.

\section{THE ANALYTIC HIERARCHY PROCESS}

The analytic hierarchy process, originally introduced by Saaty (1980), has been used to quantify and evaluate a number of complex management decisions where there are competing sets of values.

The analytic hierarchy process has been validated by several applications over several decades, both in the application of prioritization of sets of requirements (Armacost, et al., 1994; Toshtzar, 1988; Weber, 1996; Zahedi, 1985) as well as for the evaluation and selection of information technology alternatives (Arbel and Seidmann, 1984; Borthick and Scheiner, 1988; Davies, 1994; Djang, 1993; Estiva, et al. 1992; Kuei, et al., 1994; Schniederjans and Wilson, 1991; Sivarama, 1990; Vellore and Olson, 1991; Verkasalo and Parkkinen, 1991). These studies reflect the robustness of the technique when applied to complex information technology requirements within the business context.

The analytic hierarchy process has also been successfully applied to the source selection process for organizations (Cook, 1986; Nydick and Hill, 1992; Revetta, 1991; Seydel and Olson, 1990; Wan, 1988; Zhao, 1991). These studies take into account the diverse constituencies, financial, legal and organizational dimensions that must be included in the model structure to reflect a supportable decision. These dimensions add complexity to the technological requirements, but generate a more robust decision.

To implement the model, Expert Choice software from Expert Choice was selected (www.expertchoice.com). This product is a widely used implementation of the AHP produced by a company cofounded by Saaty (Expert Choice, 2008). This software provides adequate flexibility and ease of use to implement the model.

An initial set of decision criteria was developed using the set of characteristics developed during the market survey stage of the project. These were further refined during review with members of the Steering Committee. The results of this process are the model shown in Figure 4.

A two-step iterative approach was used with the representatives of the stakeholder organizations. The first iteration was used to further refine the decision criteria and to gain input on the pair-wise comparisons of the evaluation criteria. A second iteration was conducted with key decision stakeholders to review and concur on the relative weights produced and reduce areas of inconsistency. An IR ratio of .1 or less was maintained for all pairwise comparisons, falling well within acceptable limits. Figure 5 presents the factor weighting model for the source selection. 


\section{CONCLUSION}

Use of the analytic hierarchy process provides an effective way to structure and quantify source selection decisions in an environment involving several stakeholder organizations. It produces supportable conclusions that lend themselves well to reproducibility and sensitivity analysis. The iterative group techniques used in this application provided the additional advantage of focusing the process toward consensus on the relative significance of the various weighting factors and pair-wise comparisons.

\section{FOOTNOTES}

1. The research for this case was performed by the author during a contract for Marriott International.

2. The names of the actual participants have been changed.

\section{AUTHOR INFORMATION}

William Townsend is a Visiting Assistant Professor of Management at Jacksonville University. He has taught and written on management topics for over 25 years. Prior to Jacksonville University, Dr. Townsend has taught at American University, George Washington University and the University of Maryland. He has also been the President and founder of Townsend \& Company, a Washington, DC based consulting firm since 1978.

\section{REFERENCES}

1. Arbel, A. and A. Seidmann, A., Selecting a Microcomputer for Process Control and Data Acquisition, IIE Transactions, Vol. 16, No. 1, pp. 73-80, 1984.

2. $\quad$ Armacost, R.L., Componation, P., Mullens, M., and Swart, W., An AHP Framework for Prioritizing Customer Requirements in QFD: An Industrialized Housing Application, IIE Transactions, Vol. 26, No. 4, pp. 72-79, 1994.

3. Borthick, A.F.and Scheiner, J.H., Selection of Small Business Computer Systems: Structuring a MultiCriteria Approach, Journal of Information Systems, pp. 10-29, 1988.

4. Cook, C.R., Expert Support Systems for Competitive Procurement, Telematics, Vol. 3, No. 4, pp. 273-288, 1986.

5. Davies, L., Evaluating and Selecting Simulation Software Using the Analytic Hierarchy Process, Integrated Manufacturing Systems, Vol. 5, No. 1, pp. 23-32, 1994.

6. Djang, P. A., Selecting Personal Computers, Journal of Research on Computing in Education, Vol. 25, No. 3, pp. 327-328, 1993.

7. Estiva, J.C., Tummala, V.M.R. and Antiocha, S., Decision Support System for Local Area Network Procurement: A Case Study, Information Resources Management Journal, Vol. 6, No. 2, pp. 5-14, 1992.

8. Expert Choice (2008). http://www.expertchoice.com accessed 11/22/2008.

9. Kuei, C., Lin, C., Aheto, J. and Madu, C., A Strategic Decision Model for the Selection of Advanced Technology, International Journal of Production Research, Vol. 32, No. 9, pp. 2117-2130, 1994.

10. Marriott International (2008). http://www.marriott.com/corporateinfo/culture/heritageTimeline.mi accessed 11/22/2008.

11. Nydick, R.L. and Hill, R., Using the Analytic Hierarchy Process to Structure the Supplier Selection Procedure, International Journal of Purchasing \& Materials Management, Vol. 28, No. 2, pp. 31-36, 1992.

12. Revetta, J. Jr., Analytic Hierarchy Approach to CRAF Contract Proposals, Mathematical and Computer Modeling, Vol. 15, No. 9, pp. 77-85, 1991.

13. Ritz-Carlton (2008). http://corporate.ritzcarlton.com/en/About/OurHistory.htm accessed 11/22/2008.

14. Saaty, T., The Analytic Hierarchy Process: Planning, Priority Setting, Resource Allocation, New York, McGraw-Hill, ISBN 0-07-054371-2, 1980.

15. Schniederjans, M. J. and Wilson, R.L., Using the Analytic Hierarchy Process and Goal Programming for Information System Project Selection, Information \& Management, Vol. 20, No. 5, pp. 333, 1991.

16. Seydel, J. and Olson, D.L, Bids Considering Multiple Criteria, Journal of Construction Engineering and Management, Vol. 116, No. 4, pp. 609-623, 1990. 
17. Sivarama, A. V., The Analytic Hierarchy Process for Choice of Technologies: An Application, Technological Forecasting and Social Change, Vol. 38, No. 2, pp. 151, 1990.

18. Toshtzar, M., Multi-Criteria Decision Making Approach to Computer Software Evaluation: Application of the Analytic Hierarchy Process, Mathematical and Computer Modelling, Vol. 11, pp. 276-281, 1988.

19. Vellore, R. and Olson, D., An AHP Application to Computer System Selection, Mathematical and Computer Modeling, Vol. 15, No. 7, pp. 83-93, 1991.

20. Verkasalo, M. and Parkkinen, R., AHP in High Tech Production Decisions, Proceedings of the 2nd International Symposium on The Analytic Hierarchy Process, Pittsburgh, PA, pp. 319-328, 1991.

21. Wan, Y., Application of the AHP to the Evaluation of Bidders of Hydraulic Resources Capital Construction, Reprints of the International Symposium on The Analytic Hierarchy Process, Tianjin University, Tianjin, China, Sept. 6-9, pp. 587-594, 1988.

22. Weber, K., The Selection of Forecasting Methods and Software with the AHP, Proceedings of the Fourth International Symposium on the Analytic Hierarchy Process, Simon Frasier University, Burnaby, B. C., Canada, July 12-15, pp. 56-63, 1996.

23. Whipple, T.W. and Simmons, K.A., Using the Analytic Hierarchy Process to Assess Gender Differences in the Evaluation of Microcomputer Vendors, Journal of the Academy of Marketing Science, Vol. 15, No. 2, pp. 33-41, 1987.

24. Zahedi, F., Database Management System Evaluation and Selection Decision, Decision Science, Vol. 16, No. 1, pp. 91-116, 1985.

25. Zhao, X., Lu, T., and Sang, Y., AHP for Checking and Ratifying Responsible Business Contracts, Proceedings of the 2nd International Symposium on The Analytic Hierarchy Process, Pittsburgh, PA, pp. 439-450, 1991.

26. Zviran, M., A Comprehensive Methodology for Computer Family Selection, Journal of Systems and Software, Vol. 22, No. 1, pp. 17-26, 1993. 
Figure 4: Vendor Selection Criteria

\section{AHP Model of Vendor Selection}

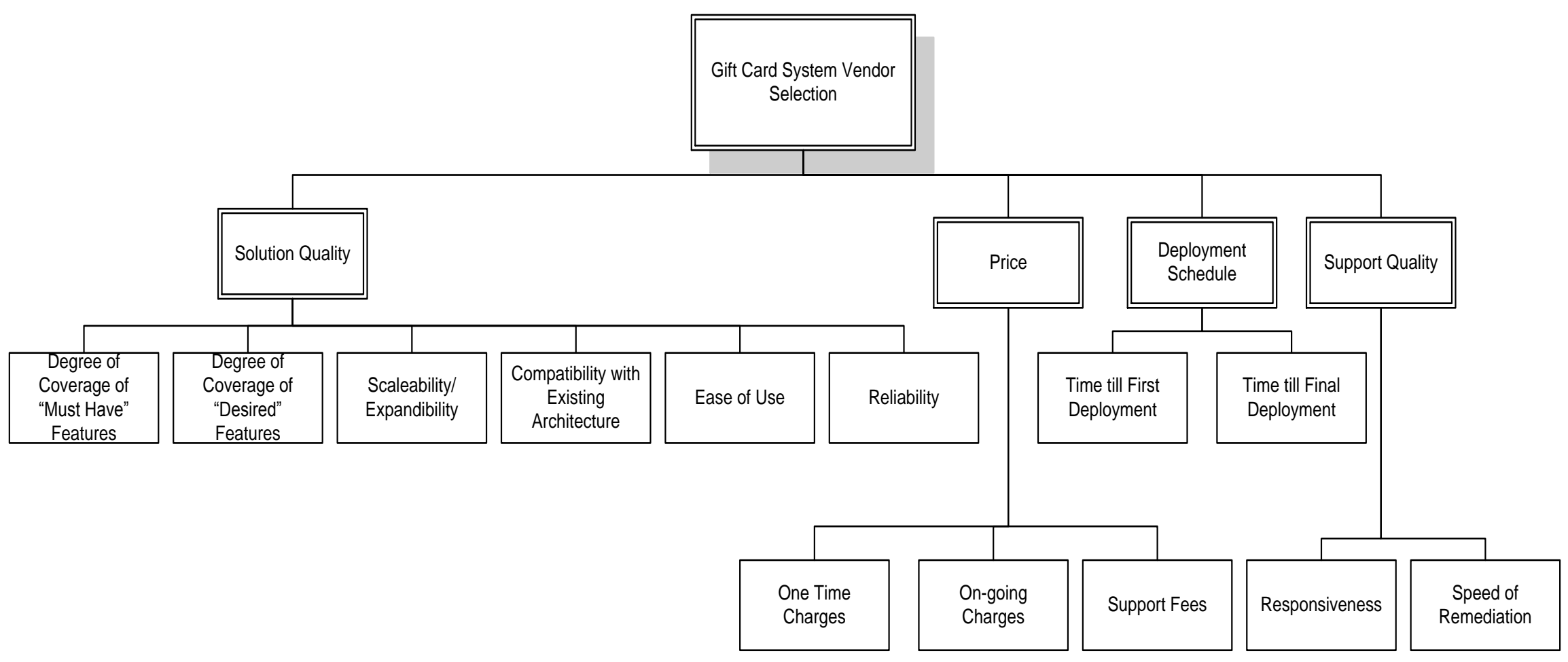


Figure 5: Factor Weighting Model

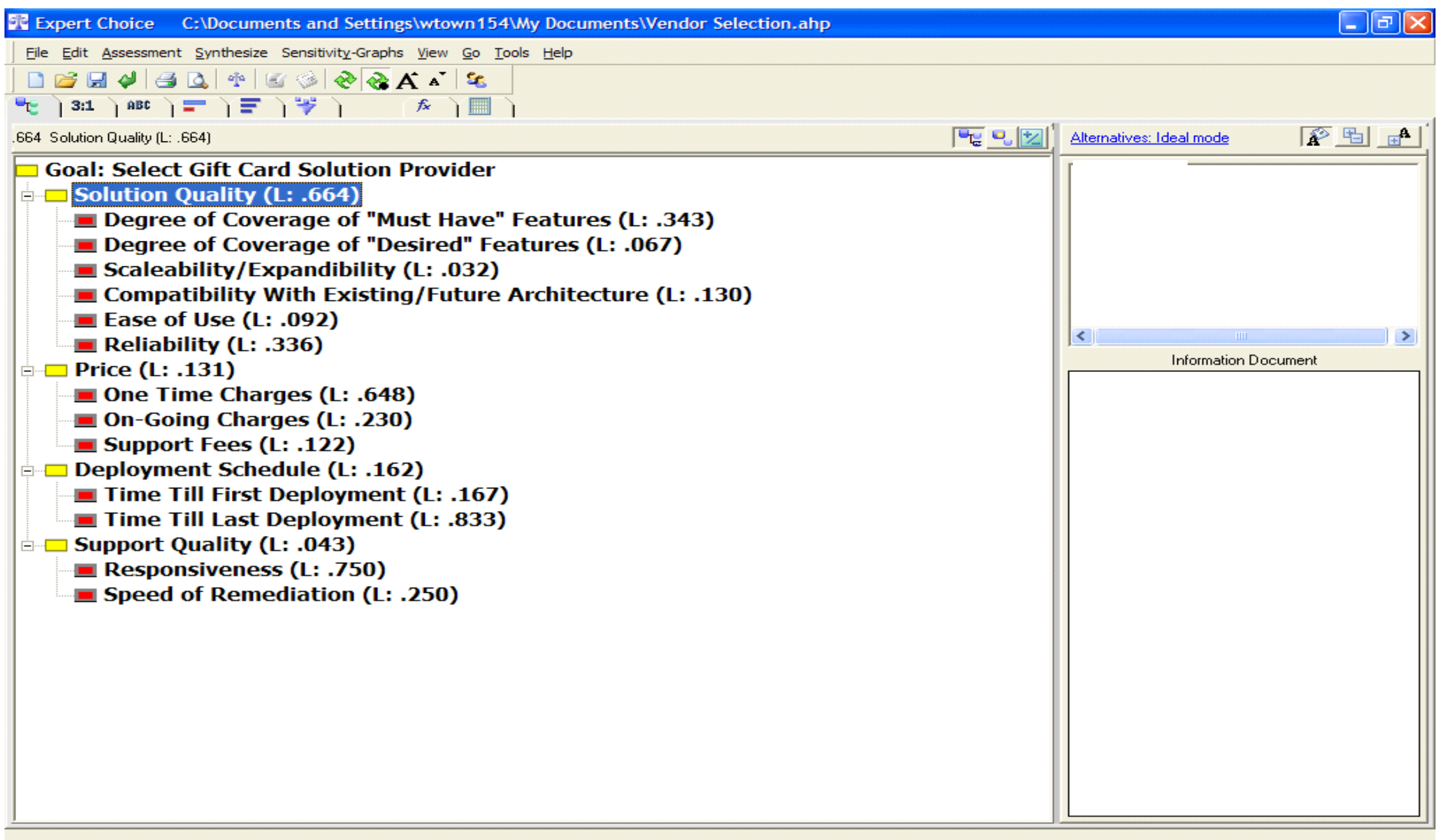

